\title{
Quantitative monitoring of diverse fish communities on a large scale combining eDNA metabarcoding and qPCR
}

Didier Pont ${ }^{1}$, Paul Meulenbroek ${ }^{1}$, Vincenz Bammer ${ }^{2}$, Tony Dejean ${ }^{3}$, Tibor Eros ${ }^{4}$, Pauline $\mathrm{Jean}^{5}$, Mirjana Lenhardt ${ }^{6}$, Christopher Nagel ${ }^{7}$, Ladislav Pekarik ${ }^{8}$, Michael Schabuss ${ }^{9}$, Bernhard Stoeckle $^{7}$, Elena Stoica ${ }^{10}$, Horst Zornig ${ }^{9}$, Alexander M. Weigand ${ }^{11}$, and Alice Valentini $^{5}$

${ }^{1}$ University of Natural Resources and Life Sciences Vienna

${ }^{2}$ Bundesamt für Wasserwirtschaft

${ }^{3}$ Spygen

${ }^{4}$ Hungarian Academy of Sciences Centre for Ecological Research Balaton Limnological Research Institute

${ }^{5}$ SPYGEN

${ }^{6}$ University of Belgrade

${ }^{7}$ Technical University of Munich

${ }^{8}$ Institut of Zoology, Slovak Academy of Sciences

${ }^{9} \mathrm{PRO}$ FISCH OG Ecological Consultants

${ }^{10}$ National Institute for Marine Research and Development Grigore Antipa

${ }^{11}$ Luxembourg National Museum of Natural History

January 24, 2022

\begin{abstract}
eDNA metabarcoding is an effective method for studying fish communities but allows only an estimation of relative species abundance (density / biomass). Here, we combine metabarcoding with an estimation of the total abundance of eDNA amplified by our universal marker (teleo) using a qPCR approach to infer the absolute abundance of fish species. We carried out a $2850 \mathrm{~km}$ eDNA survey within the Danube catchment using a spatial integrative sampling protocol coupled with traditional electrofishing for fish biomass and density estimation. Total fish eDNA concentrations and total fish abundance were highly correlated. The correlation between eDNA concentrations per taxon and absolute specific abundance was of comparable strength when all sites were pooled and remained significant when the sites were considered separately. Furthermore, a non-linear mixed model showed that species richness was underestimated when the amount of teleo-DNA extracted from a sample was below a threshold of 0.65.106 copies of eDNA. This result, combined with the decrease in teleo-DNA concentration by several orders of magnitude with river size, highlights the need to increase sampling effort in large rivers. Our results show a comprehensive description of longitudinal changes in fish communities and underline our combined metabarcoding/qPCR approach for biomonitoring and bioassessment surveys when a rough estimate of absolute species abundance is sufficient.
\end{abstract}

\section{Title and Authors}

Quantitative monitoring of diverse fish communities on a large scale combining eDNA metabarcoding and qPCR 


\title{
Running title: Fish communities eDNA quantitative monitoring
}

Didier Pont ${ }^{1}$, Paul Meulenbroek ${ }^{1,2}$, Vincenz Bammer ${ }^{3}$, Tony Dejean ${ }^{4}$, Tibor Erős ${ }^{5}$, Pauline Jean ${ }^{4}$, Mirjana Lenhardt $^{6}$, Christoffer Nagel ${ }^{7}$, Ladislav Pekarik ${ }^{8}$, Michael Schabuss ${ }^{9}$, Bernhard C. Stoeckle ${ }^{7}$, Elena Stoica ${ }^{10}$, Horst Zornig ${ }^{9}$, Alexander Weigand ${ }^{11}$, Alice Valentini ${ }^{4}$

${ }^{1}$ University of Natural Resources and Life Sciences, Vienna, Institute of Hydrobiology and Aquatic Ecosystem Management, Gregor-Mendel-Straße 33, 1180 Vienna, Austria. ${ }^{2}$ WasserCluster Lunz -Biologische Station GmbH, Dr. Carl Kupelwieser Promenade 5, 3293 Lunz am See, Austria. ${ }^{3}$ Bundesamt für Wasserwirtschaft, Institut für Gewässerökologie und Fischereiwirtschaft, Abteilung Gewässerökologie, Scharfling 18, 5310 Mondsee, Austria. ${ }^{4}$ SPYGEN, 17, rue du Lac Saint-André, Savoie Technolac, BP 274, 73375Le Bourget du Lac, France. ${ }^{5}$ Balaton Limnological Research Institute, Eötvös Lor'and Research Network (ELKH), Klebelsberg Kuno u. 3, Tihany, Hungary. ${ }^{6}$ Institute for Multidisciplinary Research, Institute for Biological Research "Siniša Stanković", National Institute of Republic of Serbia, University of Belgrade, Despota Stefana 142, Belgrade, 11000, Serbia. ${ }^{7}$ Technical University of Munich, Chair of Aquatic Systems Biology, D-85350 Freising-Weihenstephan, Germany. ${ }^{8}$ Trnava University, Faculty of Education, Priemyselná 4, 91701 Trnava, Slovakia. ${ }^{9}$ PRO FISCH OG Ecological Consultants, Hörlgasse 6/2/13, 1090 Vienna, Austria. ${ }^{10}$ National Institute for Marine Research and Development "Grigore Antipa", Blvd. Mamaia no. 300, 900581, Constanţa, România. ${ }^{11}$ National Museum of Natural History, 25 Rue Münster, 2160 Luxembourg. Correspondence and requests for materials should be addressed to D.P (didier.pont@boku.ac.at).

\begin{abstract}
eDNA metabarcoding is an effective method for studying fish communities but allows only an estimation of relative species abundance (density / biomass). Here, we combine metabarcoding with an estimation of the total abundance of eDNA amplified by our universal marker (teleo) using a qPCR approach to infer the absolute abundance of fish species. We carried out a $2850 \mathrm{~km}$ eDNA survey within the Danube catchment using a spatial integrative sampling protocol coupled with traditional electrofishing for fish biomass and density estimation. Total fish eDNA concentrations and total fish abundance were highly correlated. The correlation between eDNA concentrations per taxon and absolute specific abundance was of comparable strength when all sites were pooled and remained significant when the sites were considered separately. Furthermore, a non-linear mixed model showed that species richness was underestimated when the amount of teleo-DNA extracted from a sample was below a threshold of $0.65 .10^{6}$ copies of eDNA. This result, combined with the decrease in teleo-DNA concentration by several orders of magnitude with river size, highlights the need to increase sampling effort in large rivers. Our results show a comprehensive description of longitudinal changes in fish communities and underline our combined metabarcoding/qPCR approach for biomonitoring and bioassessment surveys when a rough estimate of absolute species abundance is sufficient.
\end{abstract}

\section{Key Words}

Environmental DNA, Fish Community, Rivers, Quantitative Monitoring, qPCR, Metabarcoding

\section{Introduction}

In recent years, the use of extra-organismal DNA has become a widespread method of monitoring vertebrate organisms in freshwater, brackish water and marine ecosystems (Lynsey R. Harper et al., 2019; Masaki Miya, 2022; Sigsgaard et al., 2020; Wang et al., 2021). Among a compilation of 358 vertebrate studies in aquatic environments using environmental DNA (eDNA) methodologies (Supplementary Data 1), fish were 
the most targeted group, followed by amphibians, mammals, reptiles, and birds (73.3, 17.4, 5.1, 2.3 and $1.8 \%$, respectively).

When targeting only one species (taxon_specific studies), conventional PCR allows the detection of species (Ficetola, Miaud, Pompanon, \& Taberlet, 2008; Jerde, Mahon, Chadderton, \& Lodge, 2011), whereas quantitative real-time PCR (qPCR) and droplet digital PCR (ddPCR) are the main eDNA methodologies for increasing the species detection sensitivity and quantifying the abundance of DNA sequences (Olsen, Lewis, Massengill, Dunker, \& Wenburg, 2016; Takahara, Minamoto, Yamanaka, Doi, \& Kawabata, 2012), enabling the indirect estimation of absolute species abundance (Wilcox et al., 2016; Yates, Glaser, et al., 2021). Species assemblages can be identified by metabarcoding after amplification via PCR of one or more genomic regions provided that the appropriate species reference database is available (Miya et al., 2015; Valentini et al., 2016). The number of reads per species is used as a proxy of the relative abundance of species (Di Muri et al., 2020; Goutte, Molbert, Guerin, Richoux, \& Rocher, 2020; Pont et al., 2018). Metabarcoding is less frequently used than taxon-specific studies (117 from a total of 358 publications) and is mainly used for fish ( $86 \%$ of papers) in marine and river ecosystems (36\% and $37 \%$ of papers, respectively, Supplementary Data $1)$.

Both taxon-specific and metabarcoding approaches are in general more efficient than traditional sampling methods for detecting species (Czeglédi et al., 2021; Hanfling et al., 2016; McElroy et al., 2020; Pont et al., 2018; Valentini et al., 2016), even if the scale of inference in space and time for an eDNA sample must be better defined (Deiner et al., 2017). Comparisons between taxon-specific and metabarcoding approaches are scarce. Additionally, the taxon-specific method has been reported to be both more robust and sensitive than metabarcoding (Bylemans, Gleeson, Hardy, \& Furlan, 2018) and equivalent to metabarcoding (Harper et al., 2018). Depth sequencing, number of technical replicates and occupancy modelling are also key factors that can improve the robustness of metabarcoding (Ficetola et al., 2015; Harper et al., 2019).

The number of eDNA copies in a sample obtained by taxon-specific studies (qPCR) is a significant proxy for both density and biomass (Doi et al., 2015; Takahara et al., 2012; Wilcox et al., 2016) but remains a rough estimate of aquatic vertebrates (Ushio et al., 2018) Ninety percent of a compilation of 63 studies identified significant relationships between eDNA concentrations and the abundance or biomass of target species (Rourke et al., 2021). However, this relationship is generally of medium strength due to the huge numbers of factors affecting the production, degradation, transport, sedimentation, and detectability of eDNA particles in relation to ecological/physiological species characteristics, advection/diffusion processes, temperature, $\mathrm{pH}$ or bacterial activities (Deiner et al., 2017; Rourke et al., 2021; Yates, Cristescu, \& Derry, 2021). A metaanalysis based on 19 studies (Matthew, Yates, Fraser, \& Derry, 2019) showed that the correlation is higher in controlled experiments than in the field ( $82 \%$ and $51 \%$ of the total variance explained, respectively), partly due to the uncertainties associated with the field estimation of organism abundance by the conventional sampling method (Di Muri et al., 2020).

Metabarcoding provides only the number of reads per taxon that are not related to the amount of corresponding eDNA extracted from the water sample. The relative number of reads is a good proxy for the relative abundance of species when the amplification efficiency is comparable for the different species. Comparison with traditional sampling methods highlights the capacity of eDNA to roughly describe the structure of a vertebrate community (Di Muri et al., 2020; Pont et al., 2018; Sard et al., 2019). Many technical factors can affect the capacity of metabarcoding to deliver "relative" quantitative results (Lamb et al., 2019), but the choice of primers, template competition and the characteristics of the mixture of species are among the most important (Piñol, Senar, \& Symondson, 2019; Taylor M. Wilcox et al., 2020). Some discrepancies are related to the bias of conventional sampling methods, especially in large water bodies (Boivin-Delisle et al., 2021; Pont et al., 2018).

Several technical options have been tested to circumvent the limitation of metabarcoding to deliver absolute quantitative multiple taxa abundance. Some authors have proposed combining eDNA and animal counts (Chambert, Pilliod, Goldberg, Doi, \& Takahara, 2018). Multiplex real-time PCR enables the simultaneous detection of several fishes (Jo, Fukuoka, Uchida, Ushimaru, \& Minamoto, 2020). HT-qPCR systems have 
been tested on fish species and validated by comparison with qPCR (Wilcox et al., 2020). Simultaneous quantification of the eDNA from fish species with qSeq gives results strongly correlated with those obtained with microfluidic ddPCR (Hoshino, Nakao, Doi, \& Minamoto, 2021). Another possibility (MiqSeq) is the enrichment of the sample with known quantities of DNA fragments from fish species absent from the water sample to estimate the copy number from the number of reads of local species obtained by metabarcoding (Ushio et al., 2018; Hoshino et al., 2021). To date, however, these experiments have only quantified a small number of species simultaneously and have not been tested on species-rich communities.

In this study, we propose a more direct method for inferring the absolute abundance of fish species from multiple sampling locations by combining eDNA metabarcoding with qPCR analysis, which assesses the total abundance of eDNA amplified by the universal marker used for metabarcoding. Fish-specific eDNA concentrations are then calculated from the ratios of fish species-specific read counts over the total read count of a sample (metabarcoding) multiplied by the total eDNA concentration estimated with qPCR (van Bleijswijk et al., 2020).

The effectiveness of this procedure was tested in a fish eDNA metabarcoding survey implemented along the Danube River from source to mouth $(2850 \mathrm{~km})$ and its major tributaries (Fig. 1). Water samples were collected from shore to shore to provide integrative sampling of the river cross section. Among the 47 sites sampled, 18 were also investigated with a conventional sampling method (traditional electrofishing, TEF) to estimate fish species abundance expressed in density or biomass per ha (Supplementary Tab. 1). We performed an eDNA metabarcoding workflow previously described (Pont et al., 2018) using the 12S mitochondrial primer for fish "teleo" (Valentini et al., 2016). The total abundance of eDNA amplified with "teleo" (teleo-DNA) was estimated by qPCR analysis. Our main objectives were (1) to verify the efficiency of our eDNA sampling strategy to correctly describe the fish communities and the ecological significance of longitudinal taxa profiles, (2) to evaluate the strength of the correlation between the estimated number of absolute total and specific eDNA copies per litre with the fish abundance obtained by using TEF, and (3) to model the influence of the total number of eDNA copies per sample on the taxa richness.

\section{Material and Methods}

\section{Site description and eDNA sampling strategy}

From the Black Forest Mountains to the Black Sea, the Danube River is the second largest European river, with a drainage area of $801,093 \mathrm{~km}^{2}$, a river length of approximately $2850 \mathrm{~km}$ and a mean discharge of 6480 $\mathrm{m}^{3} \cdot \mathrm{s}^{-1}$. The river is divided into three main sections of comparable length, namely the Upper-, Middle- and Lower Danube (Eros et al., 2017) (Fig. 1 and 6). The 18 sampled tributaries, located all along the Danube, have an average flow rate varying from 5 to $1800 \mathrm{~m}^{3} \cdot \mathrm{s}^{-1}$ (Supplementary Tab 1) and represent a very diverse range of rivers from torrential, fresh alpine rivers to large warm lowland streams (Kresser \& Laszloffy, 1964).

From June 29 to August 6, 2019, 29 and 18 sites were sampled on the Danube River and its tributaries, respectively. During this period, these rivers were close to the average hydrological conditions (Supplementary Tab 1), with a mean daily flow rate of $1716 \mathrm{~m}^{3} \cdot \mathrm{s}^{-1}$ at Vienna. The sites located on the main channel of the Danube were distributed regularly from the source to the mouth of the river. The distance between the sites (mean: $99.2 \mathrm{~km}$, standard error: $26.0 \mathrm{~km}$; range: $38-149 \mathrm{~km}$ ) was sufficient to avoid the potential influence of eDNA transported downstream from one site to the next (Pont et al., 2018). For the same reason, the sampling sites were not located within several tens of $\mathrm{km}$ downstream of the confluence of a major tributary. The tributaries were sampled 1-55 km upstream of their confluence with the Danube. Due to the failure of DNA amplification, the Inn River site was resampled in May 2020. At each site, two surface samples were collected either by wading or from a boat moving from shore to shore to provide temporal and spatial integrative sampling of the river cross section (mean filtration time of $22.34 \mathrm{MN}$ ). The water was collected with a peristaltic pump inside a disposable sterile tube and was directly filtered through a cross flow filtration capsule (VigiDNA $0.45 \mu \mathrm{m}$, SPYGEN), and its volume was measured ( 3 to $40 \mathrm{~L}$, mean of $28.73 \mathrm{~L}$ ). At the 
end of each filtration, the water in the capsule was drained, and the capsule was refilled with $80 \mathrm{~mL}$ of conservation buffer CL1 (SPYGEN) to prevent eDNA degradation.

\section{Conventional fishing}

During the same period (July 3 to August 28, 2019), 41 sites were sampled by using TEF along the Danube River and its tributaries (Bammer et al., 2021). Two additional sites were sampled in October 2018 and January 2020. The sampling procedure followed both the European Standard (CEN, 2003) and recommendations for quantitative sampling in large rivers (Schmutz, Zauner, Eberstaller, \& Jungwirth, 2001). Fish were sampled in a single pass along the bank of the main channel and in some places in the connected backwaters. The main mesohabitat types were sampled in their proportional distribution at the site level (length of river site at least 10 times the width of the river) to maximize the representativeness of the fish assemblage. The sampling effort varied between 300 and $28,412 \mathrm{~m}^{2}$, depending on the diameter of the anode (boom or hand-held) and on the river size. Fish were determined to the species level, measured $(+/-0.5$ $\mathrm{cm}$ total length) and released alive immediately afterwards. Fish individual biomass was estimated using species-specific length-weight relationships. The data for one site (Russenski Lom River) where only 19 fish were caught were discarded. Eighteen of the remaining sites were located on the same river stretch as the eDNA sampling sites (distance less than $20 \mathrm{~km}$ ), and only the main channel was sampled, allowing comparison between eDNA and TEF sampling methods at these sites (Supplementary Tab 1).

\section{eDNA metabarcoding and taxonomic assignment}

The eDNA metabarcoding workflow (extraction, amplification using "teleo" primers, high-throughput sequencing and bioinformatic analysis) was performed following a previously described protocol (Pont et al., 2018). After eDNA extraction, 12 PCR replicates were conducted per sample. Twelve libraries were prepared using the Fasteris MetaFast protocol, and twelve independent paired-end sequencing reactions $(2 \times$ $125 \mathrm{bp}$ ) was carried out on a MiSeq sequencer (Illumina) with the MiSeq Kit v3 (Illumina) following the manufacturer's instructions at Fasteris facilities. To monitor possible contaminants, eleven negative extraction controls and seven negative PCR controls (ultrapure water) were amplified with 12 replicates and sequenced in parallel with the samples. Sequence reads were analysed using programs implemented in the OBITools package (Boyer et al., 2016). The forward and reverse reads were assembled with the ILLUMINAPAIREDEND program using a minimum score of 40 and retrieving only joined sequences. Then, we assigned the reads to each sample using NGSFILTER software, and a separate data set was created for each sample by splitting the original data set into several files using OBISPLIT. After this step, we analysed each sample individually before merging the taxon list for the final ecological analysis. Strictly identical sequences were clustered together using OBIUNIQ. Sequences shorter than $20 \mathrm{bp}$, or with fewer than 10 reads or labelled "internal" by the OBICLEAN program were excluded.

To optimize the taxonomic assignment of fish eDNA collected in our water samples, we assembled, in addition to our previous database (Valentini et al., 2016), a complementary "Danubian" reference database (Supplementary Tab 3). Tissue samples for 356 specimens belonging to 73 species were collected at locations situated in the Danube catchment. Total DNA was extracted from $10 \mathrm{mg}$ of muscle tissue, amplified using the eDNA metabarcoding protocol with "teleo" primers and sequenced using a MiSeq sequencer at Fasteris facilities (Valentini et al., 2016). The sequences obtained were analysed using the ObiTools package following the same protocol as the eDNA samples excluding the taxonomic assignation step. The most abundant sequence was retrieved for reference database construction.

The final taxonomic assignment of molecular operational taxonomic units (MOTUs) was performed using the program ECOTAG, with our two reference databases and the sequences extracted from the release 142 (standard sequences) of the ENA database (http://www.ebi.ac.uk/ena). Considering the incorrect assignment of a few sequences to the sample due to tag jumps (Schnell, Bohmann, \& Gilbert, 2015), all the sequences with a frequency of occurrence $<0.001$ per sequence and per library were discarded. Then, the data were 
curated for Index-Hopping (MacConaill et al., 2018) with a threshold empirically determined per sequencing batch using experimental blanks (i.e., combinations of tags not present in the libraries) for a given sequencing batch between libraries.

The taxonomic nomenclature used referred to the European Freshwater Fish Fauna (Kottelat \& Freyhof, 2007), except for the genera Cottusand Phoxinus at the species level due to our insufficient knowledge of the haplotype diversity within the Danube catchment. The corresponding reference sequences were denominated Cot_gob and Pho_pho (see Supplementary Tab 2 for species names corresponding to eDNA detected taxa name abbreviations). When reference sequences from the different reference databases were assigned to the same species, their corresponding number of reads was cumulated. When reference sequences were assigned at the genus level, they were finally denominated at the species level when only one species from the genus was known in the catchment (Anguilla anguilla, Barbatula barbatula). If not, they were discarded (Acipenser spp., Alburnus spp., Barbus spp., Rutilus spp.), as were sequences assigned to a higher taxonomic level (Cyprinidae, Salmonidae). The molecular markers did not discriminate between 2 to 3 detected taxa belonging to the same genus (Salvelinus, Carassius, Alosa, Acipenser ,Barbus, Lampetra) and to different genera for five groups (Cypr_1, Cypr_2, Cypr_3, Cypr_4, Cypr_5). Within all groups, we only considered species-level assignment for taxa known to be present in the Danube catchment (Supplementary Tab 2). Of the two undifferentiated species in the Cypr_1 taxonomic group and present in the Danube River catchment (Chon_nas, Tel_sou), only Chon_nas was captured by using TEF during our survey. Because Tel_sou is a species well known to occur mainly in upstream fast-flowing river reaches, we considered Cypr_1 occurrence to be primarily related to the presence of Chon_nas. After the final taxonomic sequence identification, three categories of taxa were considered (see Supplementary Tab 2). The first category included all the taxa whose presence at the Danube River was confirmed (KNWTaxa) by previous traditional fish sampling surveys (Bammer et al., 2021; Eros et al., 2017) or from the literature (Kottelat \& Freyhof, 2007; Meulenbroek et al., 2018; Sommerwerk et al., 2009). The second category (WASTaxa) included food fish, farmed fish, aquarium fish or fish with any other link to human activity allowing a rejection of extra-organism eDNA in the river (mainly wastewater). The third group included species unknown in the catchment and not known for any human use (UNKTaxa).Alosa spp. were detected in the upper Danube in one sample (KM 843) with only one positive PCR. The presence of this anadromous species in such an upstream location cannot be confirmed by any previous observation and was considered a false positive at this site.

\section{Quantification of teleo_eDNA}

For the quantification of fish DNA, the samples were amplified in a real-time quantitative PCR setup using the same "teleo" primers as for metabarcoding. qPCR was performed in a final volume of $25 \mu \mathrm{L}$, which included $3 \mu \mathrm{L}$ of DNA, 12.5 $\mu \mathrm{L}$ of SYBR( $\mathrm{R}$ Green Master Mix (BioRad@), 8.3 $\mu \mathrm{L}$ of ddH2O, 0.5 $\mu \mathrm{L}$ of each "teleo" primer $(10 \mathrm{mM}), 4 \mu \mathrm{M}$ of human blocking primer (Valentini et al., 2016) and $0.2 \mu \mathrm{L}$ bovine serum albumin (BSA, Roche Diagnostic). Each sample was analysed in 3 replicates. To obtain a standard curve, a known concentration of a synthetic gene was diluted from $1,13 \times 10^{8}$ to $1,13 \times 10^{5}$ copies of DNA per reaction. The tubes containing the DNA samples were sealed, and then the qPCR standards were added to the qPCR plate in a room separate from the eDNA extraction room. The qPCR theroprofile and cycling conditions used were as follows: $95{ }^{\circ} \mathrm{C}$ for $10 \mathrm{~min}$, followed by 55 cycles of $95{ }^{\circ} \mathrm{C}$ for $30 \mathrm{~s}$ and $55{ }^{\circ} \mathrm{C}$ for 30 s. Melting curves were produced by plotting fluorescence intensity against temperature as the temperature was increased from 65 to $95{ }^{\circ} \mathrm{C}$ in $0.5{ }^{\circ} \mathrm{C}$ steps every $5 \mathrm{~s}$. The samples were analysed on a BIO-RAD $\mathbb{R}$ CFX96 Touch Real-Time PCR Detection System. To test the sensitivity of the primer for quantification, the limit of detection (LOD, i.e., the minimum amount of target DNA sequence that can be detected in the sample) and the limit of quantification (LOQ, i.e., the lowest amount of target DNA that yields an acceptable level of precision and accuracy) were calculated by running a dilution series of a known amount of synthetic gene, ranging from $1 \mathrm{ng} . \mu \mathrm{L}^{-1}\left(1.13 \times 10^{9}\right.$ DNA copies) to $10^{-9} \mathrm{ng} . \mathrm{L}^{-1}$ (1.13 DNA copies) with $12 \mathrm{qPCR}$ replicates per concentration below $10^{-3} \mathrm{ng} \cdot \mu \mathrm{L}^{-1}$. The LOQ (Klymus et al., 2019) was estimated at $10^{-7} \mathrm{ng} / \mu \mathrm{L}$, which corresponds to ca. 500 copies, and the LOD (Klymus et al., 2019) was estimated to be 80 copies. However, when performing 12 replicates, as in the case of the applied eDNA metabarcoding 
protocol, the LOD estimate was 6 DNA molecules.

The quantity of teleo-DNA per sample of KNWtaxa (eleo-DNA) was calculated from the ratio of KNWtaxa read counts over the total read count, multiplied by the teleo-DNA quantity extracted (van Bleijswijk et al., 2020). A similar computation was applied to each fish taxon, and the final concentration of fish species DNA per litre was computed from the ratio of the quantity of DNA per taxon by the volume sampled for each sample.

\section{Statistical treatments}

The mean site-specific richness calculated from the eDNA and TEF data was compared using two-tailed Student's t test for paired samples (R Core Team, 2020; package MASS, function t-test).

Teleo-DNA concentrations and fish biomass/density data were log-transformed to satisfy normality assumptions before modelling the relationship between them using a type II linear regression (R Core Team, 2020; package lmodel2, function lmodel2, "main axis" method). Teleo-DNA concentrations were regressed against the mean annual waterflow values at each site (Kresser \& Laszloffy, 1964).

The structures of fish assemblages revealed by eDNA and TEF at the 18 common sites were compared using co-inertia analysis (Doledec \& Chessel, 1994; R Core Team, 2020; package ade-4, functions dudi.pca and coinertia). This multivariate method allowed the comparison of the ordinations of two data sets to find the orthogonal co-inertia principal components that maximize the co-variance between them. The RV co-inertia criterion (0 to 1) measured the adequacy between the two tables (Dray, Chessel, \& Thioulouse, 2003) and was tested (Monte Carlo test with 10,000 permutations). We only considered common taxa with a similar level of taxonomic resolution (40 species) to test the similarity of the structure of fish assemblages obtained by the eDNA method and TEF abundance expressed in density or biomass.

To test the hypothesis that the number of KNWTaxa detected by eDNA was dependent on the quantity of teleo-DNA per sample or on the water volume (V) filtered from the 94 samples, we used an asymptotic function to describe our species-sampling effort relationship considering that, at any time, the richness $\mathrm{Y}$ is finite at a given area (Soberon \& Llorente, 1993). The choice of the non-linear function remains largely empirical (Thompson, Withers, Pianka, \& Thompson, 2003), and we chose a model (Tjorve, 2003) from the negative exponential family $\mathrm{a}^{*}\left[1-\exp ^{-\mathrm{bX}}\right]$, with an asymptotic value of richness, b proportional to the relative rate of $\mathrm{Y}$ increase while $\mathrm{X}$ increases, and $\mathrm{X}$ the sampling effort (teleo-eDNA or V). To control for variability in species richness between sites, we used non-linear mixed-effect (NLME) models (Comets, Lavenu, \& Lavielle, 2017; R Core Team, 2020; package saemix, function saemix.model, 1000 simulations) with sites as a random factor and two alternative fixed effects (teleo-eDNA, V). These two models were compared between them and to the model with only the site random effect using the AIC (Burnham \& Anderson, 2002). The significance of the fixed parameters was tested with a Wald chi-square test (Comets et al., 2017), the normality of the residuals with a Shapiro test, and the goodness of fit of the selected model by comparing the observed and predicted values at the individual level.

\section{Results}

\section{eDNA detected taxa list and comparison with conventional sampling}

The total numbers of sequence reads obtained before and after quality control (metabarcoding bioinformatic process) were $45.999 \times 10^{6}$ and $36.820 \times 10^{6}$, respectively. A total of $53.589 \times 10^{3}$ reads assigned to UNKTaxa were discarded. A total of $474.323 \times 10^{3}$ reads were assigned to WASTaxa. All the remaining reads were assigned to KNWTaxa. The final mean sequencing depth was 34,161 per positive PCR replicate (range $90 \times 10^{3}$ to $\left.179.209 \times 10^{3}\right)$. 
Out of a total of 86 taxa detected after the bioinformatic process and reassignment procedure (see Supplementary Tab 1 for taxa abbreviation list), five were classified as UNKTaxa (Bar_med, Eso_cis, Onc_cla, Onc_mas, Ric_bal) and 21 as WASTaxa. Among WASTaxa (Fig. 2), the two most abundant (Onc_myk and Sal_spp) were detected at 15 and 7 of the 47 sites, respectively, in the Upper Danube and its tributaries. Most of the other taxa were marine species detected mainly ( $71 \%$ of the total number of occurrences) downstream from Vienna (7 taxa) and on two tributaries, the Arges River ( 8 taxa) and the Russenki Lom River (5 taxa). Of the 60 remaining taxa classified as KNWTaxa (Supplementary Tab 1), 48 were identified at the species level, eight at the genus level, and four at a higher taxonomic level (taxa groups).

When only considering the 18 sites sampled with both TEF and eDNA, 40 of the 62 species caught by using TEF were also detected at the species level by using eDNA. Eighteen of the remaining species were detected by using eDNA at a higher taxonomic level. Eight species-specific taxa ("Aci_gue", "Aci_rut", "Aci_ste", "Bar_car", "Ben_sp", "Pun_pla", "Rom_ura", "Umb_kra") and one taxa group (Cor. sp.) were detected only by using eDNA. Four species ("Clu_cul", "Eud_dan", "Eud_mar", "Neo_eur") were caught only by using TEF. Despite the lack of discrimination between certain species by using eDNA, the taxon richness per site obtained by using eDNA was higher than that obtained by using TEF (Fig. 3), with mean richness values of 29.7 and 21.6, respectively (Student's t test, $\mathrm{t}=5.2147 \mathrm{df}=17, p<0.001$ ). The difference was slightly greater when species caught by using TEF were grouped together following the taxonomic assignment used for the eDNA taxa (mean TEF species richness of 20.17, $\mathrm{t}=6.1429$, $\mathrm{df}=17, p<0.001$ ).

\section{Comparison between absolute eDNA copy concentration and TEF abundance}

The average amount of teleo-DNA per sample was 4,130,634 DNA copies (range 50,676 to 23,684,000), corresponding to an average concentration of $1,223,819$ DNA copies per litre (range 7,219 to $9,046,465$ ). The concentration of teleo-DNA per site decreased along the first $500 \mathrm{~km}$ of the Danube and remained stable downstream (Fig. 4). The teleo-DNA concentrations in the tributaries were significantly higher than those in the Danube (Student's t test, $\mathrm{t}=-5.231, \mathrm{df}=44.987, p<0.001$ ). For all 47 sites, the teleo-DNA concentrations were negatively correlated with the mean water flow (Fig. 4, Pearson's R coefficient $=-0.740$, $\mathrm{n}=47, p<0.001)$.

The total fish density and biomass estimated by TEF at the 18 common sites were strongly correlated with the teleo-eDNA concentrations (Fig. 5): Pearson's R coefficients of $0.821(\mathrm{n}=18, \mathrm{P}=0.00002)$ and $0.760(\mathrm{n}$ $=18, p<0.001)$, respectively. When all the common sites were combined, the correlation between the taxaspecific eDNA concentration per litre and the species-specific abundance/biomass per ha was of comparable intensity: Pearson's $\mathrm{R}$ coefficients of $0.763(\mathrm{n}=40, p<0.001)$ and $0.673(\mathrm{n}=40, p<0.001)$, respectively. When the sites and species were differentiated, the concentration of taxa-specific eDNA per litre at each site remained significantly correlated with the specific density and biomass per ha estimated from TEF samples but with a lower intensity (Fig. 5): Pearson's R coefficients of $0.527(\mathrm{n}=224, p<0.001)$ and $0.397(\mathrm{n}=$ $224, p<0.001)$, respectively.

The co-inertia analysis showed a high level of similarity between the structure of the fish assemblages revealed by using eDNA (taxa-specific number of DNA copies per litre) and TEF (specific number of fish caught per ha) at the 18 common sites with RV co-inertia criteria of $0.797(\mathrm{p}<0.001)$ and $0.984(p<0.001)$ when the TEF data were expressed in density and biomass, respectively. The coordinates of the eDNA and TEF samples were highly correlated on the first and second co-inertia factors for TEF expressed as density (Pearson's R coefficient $=0.982, p<0.001$ ) or as biomass (Pearson's $\mathrm{R}$ coefficient $=0.993, p<0.001$ ). A direct comparison of the longitudinal distributions of species/taxa obtained with the two methods confirmed their similarity (Supplementary Fig. 1).

The change in the concentrations of the specific taxa DNA copies per litre from the source to the mouth of the Danube River provides evidence of a succession of species (Fig. 6). Bar_bar, Cot_gob, Huc_huc, Lam_pla, Pho_pho and Thy_thy were restricted to the upper Danube, while Aci_rut, Neo_flu, Sab_bal, and Sca_ery were detected from Vienna to the mouth of the Danube. Abr_bra, Alb_alb, Cyp_car, Sil_gla and 
Zin_str were detected along the entire course of the river. Syn_aba and Alo_spp. were only present in the lower Danube, but Alo_spp. was also detected $12 \mathrm{~km}$ upstream from Iron Gate I (Fig. 6). Aci_ste and Umb_kra were limited to the Danube delta.

\section{Relationship between the quantity of teleo-DNA extracted and taxonomic rich- ness}

The relationship between the number of teleo-DNA copies extracted from a water sample and the number of taxa detected was tested using non-linear mixed-effects (NLME) models with sites as a random factor and two alternative fixed effects: teleo-DNA and water volume $(\mathrm{V})$.

The non-linear mixed-effects (NLME) models with teleo-eDNA as a fixed effect had a lower Akaike information criterion (AIC) value than the NLME model with only the random effect (site identity): AIC values of 566.63 and 600.67 , respectively. The Wald chi-square test showed a significant effect for the fixed-effect teleo-eDNA (Wald Chi-squared test $=29.973, \mathrm{df}=1, p<0.001$ ). The NLME model with the water volume sampled $(\mathrm{V})$ as a fixed effect had a higher AIC value than the NLME model with only the random effect (835.28 versus 600.67), and V was not significant (Wald chi-square test $=1.004$, df $=1, p>0.05$ ). For the best model including teleo-eDNA (Fig. 7), the Pearson's R coefficient between the observed and predicted values at the individual level was $0.959(\mathrm{n}=94, p<0.001)$, and the residuals were normally distributed (Shapiro test, $\mathrm{W}=0.994, p>0.05$ ). Asymptotic richness per site and relative growth coefficient estimates and their associated standard errors at the population level were $27.29( \pm 0.75)$ and $4.55( \pm 0.83)$, respectively, for fixed effects and $17.96( \pm 5.06)$ and $4.49( \pm 0.3 .06)$, respectively, for random effects. At the individual level, asymptotic richness and relative growth coefficients varied from 19.34 to 34.42 and from 0.1793 to 6.2658 , respectively, with only one relative growth coefficient value less than 1 (Enns River).

The predicted value of teleo-eDNA needed to detect $95 \%$ of the taxa richness was $0.651 \times 10^{6}$ DNA copies when considering the model parameters defined at the population level. At the individual (site) level, this amount varied from $0.252 \times 10^{6}$ to $2.520 \times 10^{6}$ DNA copies after excluding the Enns River site (value of $15.4040 \times 10^{6}$ DNA copies).

\section{Discussion}

The fish communities of our sampling sites along the Danube and near the mouths of its main tributaries are well known both in terms of the fish species list and the assemblage structure (Eros et al., 2017; Kottelat \& Freyhof, 2007; Sommerwerk et al., 2009); thus, these communities are useful for testing the effectiveness of an eDNA metabarcoding strategy. From a total of 86 taxa detected during our study, only five were UNKTaxa in the Danube catchment (Kottelat \& Freyhof, 2007; Sommerwerk et al., 2009). For most of these taxa, the main explanation is probably a misassignment of the detected sequences in relation to insufficient knowledge of their regional haplotype variability. Richardsonius balteatus, a North American species, Barbus meridionalis , present in rivers draining to the northwestern Mediterranean basin, andEsox cisalpinus occurring in central and northern Italy (Kottelat \& Freyhof, 2007) are species whose teleosequences are close to those of Squalius cephalus, Barbus barbus and Esox lucius,respectively. Oncorhynchus clarkii and Oncorhynchus masou, two salmonid species inhabiting the northern Pacific Ocean, may also have been confused with 0nc_Myk, but they have also been introduced into European fish farms (Crawford \& Muir, 2008), and hybridization with other Salmonid species is conceivable (Chevassus, 1979). The development of a more comprehensive local reference database would reduce this risk of misassignment.

The WASTaxa category of taxa was composed mainly of food fish according to the eDNA present in urban wastewater. Most of these taxa were detected at only three sites: immediately downstream of the wastewater discharge point of the city of Vienna, on the Argès River and on the Russemski Lom River. The latter two rivers are known to receive insufficiently treated municipal wastewater (Frincu, 2021; Kirschner et al., 2021). eDNA released into the river from wastewater treatment plants can lead to false-positive detection results, 
and a good knowledge of the regional fauna is needed to identify them. Notably, the detection of marine food fish is a clear sign of local pollution and can be incorporated as a criterion for future bioassessment methods based on eDNA samples (Pont et al., 2021). Two other taxa (0nc_Myk, Sal_spp) are also known as food fish and farmed fish (https://www.helgilibrary.com/indicators/fish-consumption-per-capita/austria/), but they are also regularly present in the Upper Danube and its tributaries, mainly due to stocking (Stankovic, Crivelli, \& Snoj, 2015). Therefore, the presence of their eDNA must be interpreted with caution when detected in a water body that does not correspond to one of their known habitats.

A total of 60 taxa known to occur in the Danube River catchment (KNWTaxa) were detected. In addition to the 48 taxa assigned at the species level, the 12 taxa assigned at a higher taxonomic level corresponded to a potential of 26 well-known Danubian species, giving a maximum number of 74 species detected. This value was comparable to the total of 71 species caught in the TEF survey conducted in the same period (Bammer et al., 2021). When considering only the 18 sites sampled with both TEF and eDNA, all the species caught by using TEF were detected by using eDNA except four (Clupeonella cultriventris, Eudontomyzon danfordi, Eudontomyzon mariae, Neogobius eurycephalus ), but they were not recorded in our DNA reference database. Six of the eight taxa (Aci_gue, Aci_rut, Aci_ste, Bar_car, Ben_sp, Rom_ura) detected only by using eDNA were benthic species (Kottelat \& Freyhof, 2007) inhabiting mainly the Danube itself or its coarse-bottomed tributaries. Similarly, the higher taxonomic richness obtained by using eDNA confirmed the ability of this method to be representative of all fish fauna, especially in deep rivers where a single traditional sampling technique does not allow sampling of the whole river section (Eros et al., 2017). Our results highlight the effectiveness of our integrative sampling strategy in space (the whole section of the river) and time (approximately half an hour) as well as the performance of the teleo primer, even if its discriminating power for some species is limited. For the latter, the analysis of another marker in parallel, such as MiFish, can allow more species to be discriminated (Polanco et al., 2021).

One of the most original aspects of this study is the strong correlation between teleo-eDNA concentrations and fish abundance estimated by using TEF at 18 common sites. The efficiency of eDNA qPCR data to correctly estimate taxa-specific abundance is well documented (Rourke et al., 2021), but the estimation of the total fish abundance from the total fish eDNA concentration (primer qPCR analysis) has been tested only in an estuarine environment at three sites only a few kilometres apart (van Bleijswijk et al., 2020). Here, we demonstrate the capability of eDNA metabarcoding to estimate the total absolute abundance of fish at distant sites, i.e., independent of their eDNA contents, and in a large range of river sizes. The intensity of the correlation between the teleo-eDNA concentration and fish abundance is comparable to results obtained in species-specific qPCR studies in natural environments (Yates et al., 2019). The difference in correlation intensity with fish abundance observed when the eDNA concentration is expressed as density or biomass should be viewed with caution, as no significant effect of the fish abundance metric was found (Yates et al., 2019). The ratios of fish species-specific read counts over the total read count of a sample multiplied by the teleo-eDNA concentration measured with qPCR (van Bleijswijk et al., 2020) were significantly correlated with the fish species abundance obtained by using TEF. This correlation was higher when all sites were pooled, which highlights the agreement between the two methods for all the species and the importance of uncertainties associated with the site scale with both eDNA and TEF.

The very high values of the co-inertia criteria also demonstrate that the descriptions of fish community structures obtained with the TEF (abundance per ha) and eDNA methods (taxa-specific DNA copy numbers per litre) were quite similar. The distribution of species along the entire Danube River obtained by using eDNA was consistent with previous knowledge (Eros et al., 2017) but with a lower between-site variability. For example, Aci_rut, a resident sturgeon species, was regularly detected downstream of the first $1000 \mathrm{~km}$ of the river by using eDNA, whereas no or few individuals were captured by using traditional methods (Bammer et al., 2021; Eros et al., 2017). The anadromous taxa Alo_spp (Alosa immaculata / A. tanaica) was detected by using eDNA in almost all the sites located downstream of the Iron Gate dams that are known to limit their upstream migration (Sommerwerk et al., 2009). In addition, the detection of Alo_spp $12 \mathrm{~km}$ upstream of Iron Gate I dam (KM 1908) is consistent with previous captures of Alosa tanaicaindividuals upstream of Iron Gate II (M. Lenhardt, pers. comm.). 
Nevertheless, eDNA is only an indirect estimator of organism abundance and is influenced by many physiological processes and environmental conditions, and the uncertainties associated with all factors affecting eDNA concentration in the environment are high (Rourke et al., 2021). eDNA cannot be expected to provide a highly accurate quantification of the fish populations as needed for precise fish stock estimations in fisheries (Boivin-Delisle et al., 2021; Rourke et al., 2021; Yates, Cristescu, et al., 2021). For such a purpose, recent technical options could provide a good alternative (Hoshino et al., 2021; Sato et al., 2021; Taylor M. Wilcox et al., 2020; Ushio et al., 2018). However, it must also be considered that most conventional fish sampling methods are associated with many biases and high uncertainties, especially in large water bodies where the spatial representativeness of samples is limited and multiple methods must be used (Eros et al., 2017; Zajiceke \& Wolter, 2018). For most biomonitoring purposes, a rough estimation of absolute fish abundance is sufficient, as the main objective is to compare fish assemblages on a large scale or to detect long-term variability in relation to changes in anthropogenic disturbances.

An additional benefit of quantifying total fish eDNA by qPCR is to optimize sampling effort. Our NLME models showed that the species richness was underestimated when the amount of teleo-eDNA extracted from a sample was below a threshold of $0.65 .10^{6}$ eDNA copies. Although several authors have recognized the importance of this parameter (Shu, Ludwig, \& Peng, 2020; Wang et al., 2021), to our knowledge, no studies have quantified its influence. In addition, our results demonstrated the significant influence of river size on the concentration of teleo-eDNA per litre, with values 10 to 100 times lower in larger rivers. This can be due to different processes, e.g., dilution of eDNA with increasing river depth, as most fish species are confined to the river bottom or shoreline, or the decreased abundance of fish in large rivers compared to small rivers. Further research is needed to better understand the processes that explain such a pattern. As the quantity of teleo-eDNA extracted depends on both its concentration per litre and the water volume sampled, the water volume needed to extract an amount of eDNA over the threshold of $0.65 \times 10^{6} \mathrm{eDNA}$ copies is approximately 40 litres for large rivers but only a few litres for smaller rivers. The volume of water to be sampled is the main issue in many studies, with values ranging from less than a litre to $68 \mathrm{~L}$ (Cantera et al., 2019; Civade et al., 2016; Doi et al., 2017), but no general guidelines have been established (Shu et al., 2020; Wang et al., 2021). This study highlights that river size is one of the main factors that influences the minimum water volume to be sampled. Nevertheless, this result is only valid in the context of our spatial and temporal integrative sampling strategy: the total volume collected must be sufficient to allow the collection of eDNA from the entire river section.

In conclusion, our results show that the combination of qPCR analysis to estimate the total concentration eDNA amplified by the "teleo" primer, an eDNA metabarcoding workflow with a high number of technical replicates, and an integrative sampling strategy allows a correct estimation of species diversity and delivers a good proxy of absolute species abundance (based on taxa-specific DNA copy numbers per litre). Our approach is not appropriate if accurate abundance estimation is required, such as in intensively managed fisheries. However, we consider it sufficient for most biomonitoring and bioassessment purposes, especially given the limited effectiveness of conventional fish sampling methods in most aquatic ecosystems. The efficiency of our procedure needs to be tested in ponds and lakes, estuaries, and marine environments. Our results should inspire a more quantitative approach to aquatic community analysis using eDNA methods.

\section{Acknowledgements}

This work was carried out in the framework of the Fourth Joint Danube Survey (JDS4) and was led and funded by the International Commission for the Protection of the Danube River (I.C.P.D. R) and in collaboration with the EU COST Action DNAqua-Net (CA15219) and the INTEREG MEASURES programme (DTP2-038-2.3). Additional funding was provided by the Austrian Federal Ministry of Agriculture, Regions and Tourism (BMLRT) and the ÖK-IAD (Österreichisches Komitee der Internationalen Arbeitsgemeinschaft Donauforschung). This publication is also part of the bilateral Austrian-Hungarian Joint Research Project RIMECO "Functioning of vertebrate metacommunities in dynamic riverine landscapes: an innovative ap- 
proach using eDNA metabarcoding" supported by the Austrian Science Fund (FWF) (I 5006) and the ANN-OTKA (141884) grant. We thank SPYGEN staff for their help in eDNA analysis in the laboratory.

\section{References}

Bammer, V., Apostolou, A., Bulat, D., Effenberger, M., Erős, T., Hortic, S., . . . Simonović, P. (2021). Fish. In I. Liška, F. Wagner, M. Sengl, K. Deutsch, J. Slobodník, \& M. Paunović (Eds.), Joint Danube survey 4 Scientific Report: A Shared Analysis of the Danube River (pp. 41-54). (ICPDR Ed.). Vienna.

Boivin-Delisle, D., Laporte, M., Burton, F., Dion, R., Normandeau, E., \& Bernatchez, L. (2021). Using environmental DNA for biomonitoring of freshwater fish communities: Comparison with established gillnet surveys in a boreal hydroelectric impoundment. Environmental DNA, 3(1), 105-120. doi:https://doi.org/10.1002/edn3.135

Boyer, F., Mercier, C., Bonin, A., Le Bras, Y., Taberlet, P., \& Coissac, E. (2016). OBITOOLS: a UNIX-inspired software package for DNA metabarcoding. Molecular Ecology Resources, 16(1), 176-182. doi:10.1111/1755-0998.12428

Burnham, K. P., \& Anderson, D. R. (2002). Model Selection and Multimodel Inference: A Practical Information-Theoretical Approach (Springer Ed.). New York.

Bylemans, J., Gleeson, D. M., Hardy, C. M., \& Furlan, E. (2018). Toward an ecoregion scale evaluation of eDNA metabarcoding primers: A case study for the freshwater fish biodiversity of the Murray-Darling Basin (Australia). Ecology and Evolution, 8(17), 8697-8712. doi:10.1002/ece3.4387

Cantera, I., Cilleros, K., Valentini, A., Cerdan, A., Dejean, T., Iribar, A., . . . Brosse, S. (2019). Optimizing environmental DNA sampling effort for fish inventories in tropical streams and rivers. Scientific Reports, 9(1), 3085-3085. doi:10.1038/s41598-019-39399-5

CEN (2003). EN 14011 - Water quality - Sampling of fish with electricity. Retrieved from

Chambert, T., Pilliod, D. S., Goldberg, C. S., Doi, H., \& Takahara, T. (2018). An analytical framework for estimating aquatic species density from environmental DNA. Ecology and Evolution, 8(6), 3468-3477. doi:10.1002/ece3.3764

Chevassus, B. (1979). Hybridization in salmonids - Results and perspectives. Aquaculture, 17(2), 113-128. doi:10.1016/0044-8486(79)90047-4

Civade, R., Dejean, T., Valentini, A., Roset, N., Raymond, J. C., Bonin, A., . . . Pont, D. (2016). Spatial Representativeness of Environmental DNA Metabarcoding Signal for Fish Biodiversity Assessment in a Natural Freshwater System. Plos One, 11(6). doi:10.1371/journal.pone.0157366

Comets, E., Lavenu, A., \& Lavielle, M. (2017). Parameter Estimation in Nonlinear Mixed Effect Models Using saemix, an R Implementation of the SAEM Algorithm. Journal of Statistical Software, 80(3), 1-41.

Crawford, S. S., \& Muir, A. M. (2008). Global introductions of salmon and trout in the genus Oncorhynchus: 1870-2007. Reviews in Fish Biology and Fisheries, 18(3), 313-344. doi:10.1007/s11160-007-9079-1

Czeglédi, I., Sály, P., Specziár, A., Preiszner, B., Szalóky, Z., Maroda, Á., . . Erős, T. (2021). Congruency between two traditional and eDNA-based sampling methods in characterising taxonomic and trait-based structure of fish communities and community-environment relationships in lentic environment. Ecological Indicators, 129. doi:10.1016/j.ecolind.2021.107952

Deiner, K., Bik, H. M., Machler, E., Seymour, M., Lacoursiere-Roussel, A., Altermatt, F., . . . Bernatchez, L. (2017). Environmental DNA metabarcoding: Transforming how we survey animal and plant communities. Molecular ecology, 26(21), 5872-5895. doi:10.1111/mec.14350 
Di Muri, C., Lawson Handley, L., Bean, C. W., Li, J., Peirson, G., Sellers, G. S., . . . Hänfling, B. (2020). Read counts from environmental DNA (eDNA) metabarcoding reflect fish abundance and biomass in drained ponds. Metabarcoding and Metagenomics, 4. doi:10.3897/mbmg.4.56959

Doi, H., Uchii, K., Matsuhashi, S., Takahara, T., Yamanaka, H., \& Minamoto, T. (2017). Isopropanol precipitation method for collecting fish environmental DNA. Limnology and Oceanography-Methods, 15(2), 212-218. doi:10.1002/lom3.10161

Doi, H., Uchii, K., Takahara, T., Matsuhashi, S., Yamanaka, H., \& Minamoto, T. (2015). Use of Droplet Digital PCR for Estimation of Fish Abundance and Biomass in Environmental DNA Surveys. Plos One, 10(3), 11. doi:10.1371/journal.pone.0122763

Doledec, S., \& Chessel, D. (1994). Co-inertia analysis - An alternative method for studying species environment relationships. Freshwater Biology, 31(3), 277-294. doi:10.1111/j.1365-2427.1994.tb01741.x

Dray, S., Chessel, D., \& Thioulouse, J. (2003). Co-inertia analysis and the linking of ecological data tables. Ecology, 84(11), 3078-3089. doi:10.1890/03-0178

Eros, T., Bammer, V., Gyorgy, A. I., Pehlivanov, L., Schabuss, M., Zornig, H., . . . Szaloky, Z. (2017). Typology of a Great River Using Fish Assemblages: Implications for the Bioassessment of the Danube River. River Research and Applications, 33(1), 37-49. doi:10.1002/rra.3060

Ficetola, G. F., Miaud, C., Pompanon, F., \& Taberlet, P. (2008). Species detection using environmental DNA from water samples. Biology Letters, 4(4), 423-425. doi:10.1098/rsbl.2008.0118

Ficetola, G. F., Pansu, J., Bonin, A., Coissac, E., Giguet-Covex, C., De Barba, M., . . Taberlet, P. (2015). Replication levels, false presences and the estimation of the presence/absence from eDNA metabarcoding data. Molecular Ecology Resources, 15(3), 543-556. doi:10.1111/1755-0998.12338

Frincu, R. M. (2021). Long-Term Trends in Water Quality Indices in the Lower Danube and Tributaries in Romania (1996-2017). International Journal of Environmental Research and Public Health, 18(4). doi:10.3390/ijerph18041665

Goutte, A., Molbert, N., Guerin, S., Richoux, R., \& Rocher, V. (2020). Monitoring freshwater fish communities in large rivers using environmental DNA metabarcoding and a long-term electrofishing survey. J Fish Biol, 97(2), 444-452. doi:10.1111/jfb.14383

Hanfling, B., Handley, L. L., Read, D. S., Hahn, C., Li, J. L., Nichols, P., . . . Winfield, I. J. (2016). Environmental DNA metabarcoding of lake fish communities reflects long-term data from established survey methods. Molecular ecology, 25(13), 3101-3119. doi:10.1111/mec.13660

Harper, L. R., Handley, L. L., Hahn, C., Boonham, N., Rees, H. C., Gough, K. C., . . Hanfling, B. (2018). Needle in a haystack? A comparison of eDNA metabarcoding and targeted qPCR for detection of the great crested newt (Triturus cristatus). Ecology and Evolution, 8(12), 6330-6341. doi:10.1002/ece3.4013

Harper, L. R., Lawson Handley, L., Carpenter, A. I., Ghazali, M., Di Muri, C., Macgregor, C. J., . . Hänfling, B. (2019). Environmental DNA (eDNA) metabarcoding of pond water as a tool to survey conservation and management priority mammals. Biological Conservation, 238. doi:10.1016/j.biocon.2019.108225

Hoshino, T., Nakao, R., Doi, H., \& Minamoto, T. (2021). Simultaneous absolute quantification and sequencing of fish environmental DNA in a mesocosm by quantitative sequencing technique. Scientific Reports, 11(1). doi:10.1038/s41598-021-83318-6

Jerde, C. L., Mahon, A. R., Chadderton, W. L., \& Lodge, D. M. (2011). "Sight-unseen" detection of rare aquatic species using environmental DNA. Conservation Letters, 4(2), 150-157. doi:10.1111/j.1755263X.2010.00158.x

Jo, T., Fukuoka, A., Uchida, K., Ushimaru, A., \& Minamoto, T. (2020). Multiplex real-time PCR enables the simultaneous detection of environmental DNA from freshwater fishes: a case study of three exotic and three 
threatened native fishes in Japan. Biological Invasions, 22(2), 455-471. doi:10.1007/s10530-019-02102-w

Kirschner, A. K. T., Schachner, I., Jakwerth, S., Savio, D., Toth, E., Kolarevic, S., . . . Farnleitner, A. H. (2021). Microbial faecal pollution and source tracking. In I. Liška, F. Wagner, M. Sengl, K. Deutsch, J. Slobodník, \& M. Paunović (Eds.), Joint Danube survey 4 Scientific Report: A Shared Analysis of the Danube River (pp. 183-192). Vienna: ICPDR.

Klymus, K. E., Merkes, C. M., Allison, M. J., Goldberg, C. S., Helbing, C. C., Hunter, M. E., . . . Richter, C. A. (2019). Reporting the limits of detection and quantification for environmental DNA assays. Environmental DNA, 2(3), 271-282. doi:10.1002/edn3.29

Kottelat, M., \& Freyhof, J. (2007). Handbook of European freshwater fishes. Berlin: Kottelat (Privately published).

Kresser, W., \& Laszloffy, W. (1964). Hydrologie du Danube. La Houille Blanche, 2, 133-178.

Lamb, P. D., Hunter, E., Pinnegar, J. K., Creer, S., Davies, R. G., \& Taylor, M. I. (2019). How quantitative is metabarcoding: A meta-analytical approach. Molecular ecology, 28(2), 420-430. doi:https://doi.org/10.1111/mec.14920

MacConaill, L. E., Burns, R. T., Nag, A., Coleman, H. A., Slevin, M. K., Giorda, K., . . . Thorner, A. R. (2018). Unique, dual-indexed sequencing adapters with UMIs effectively eliminate index crosstalk and significantly improve sensitivity of massively parallel sequencing. Bmc Genomics, 19. doi:10.1186/s12864017-4428-5

McElroy, M. E., Dressler, T. L., Titcomb, G. C., Wilson, E. A., Deiner, K., Dudley, T. L., . . . Jerde, C. L. (2020). Calibrating Environmental DNA Metabarcoding to Conventional Surveys for Measuring Fish Species Richness. Frontiers in Ecology and Evolution, 8.

Meulenbroek, P., Drexler, S., Huemer, D., Gruber, S., Krumbock, S., Rauch, P., . . . Waidbacher, H. (2018). Species-specific fish larvae drift in anthropogenically constructed riparian zones on the Vienna impoundment of the River Danube, Austria: Species occurrence, frequencies, and seasonal patterns based on DNA barcoding. River Research and Applications, 34(7), 854-862. doi:10.1002/rra.3303

Miya, M. (2022). Environmental DNA Metabarcoding: A Novel Method for Biodiversity Monitoring of Marine Fish Communities. Annual review of marine science, 14(1), null. doi:10.1146/annurev-marine041421-082251

Miya, M., Sato, Y., Fukunaga, T., Sado, T., Poulsen, J. Y., Sato, K., . . . Iwasaki, W. (2015). MiFish, a set of universal PCR primers for metabarcoding environmental DNA from fishes: detection of more than 230 subtropical marine species. Royal Society open science, 2(7), 33. doi:10.1098/rsos.150088

Olsen, J. B., Lewis, C. J., Massengill, R. L., Dunker, K. J., \& Wenburg, J. K. (2016). An evaluation of target specificity and sensitivity of three qPCR assay for detecting environmental DNA from Northern Pike (Esox lucius) (vol 7, pg 615, 2015). Conservation Genetics Resources, 8(1), 89-89. doi:10.1007/s12686-016-0526-y

Piñol, J., Senar, M. A., \& Symondson, W. O. C. (2019). The choice of universal primers and the characteristics of the species mixture determine when DNA metabarcoding can be quantitative. Molecular ecology, 28(2), 407-419. doi:https://doi.org/10.1111/mec.14776

Polanco F, A., Richards, E., Flück, B., Valentini, A., Altermatt, F., Brosse, S., . . . Pellissier, L. (2021). Comparing the performance of $12 \mathrm{~S}$ mitochondrial primers for fish environmental DNA across ecosystems. Environmental DNA, n/a(n/a). doi:10.1002/edn3.232

Pont, D., Rocle, M., Valentini, A., Civade, R., Jean, P., Maire, A., . . . Dejean, T. (2018). Environmental DNA reveals quantitative patterns of fish biodiversity in large rivers despite its downstream transportation. Scientific Reports, 8, 13. doi:10.1038/s41598-018-28424-8 
Pont, D., Valentini, A., Rocle, M., Maire, A., Delaigue, O., Jean, P., \& Dejean, T. (2021). The future of fishbased ecological assessment of European rivers: from traditional EU Water Framework Directive compliant methods to eDNA metabarcoding-based approaches. J Fish Biol, 98(2), 354-366. doi:10.1111/jfb.14176

R Core Team (2020). R software v.4.03. A language and environment for statistical computing. Vienna, Austria: $\mathrm{R}$ foundation for statistical Computing.

Rourke, M. L., Fowler, A. M., Hughes, J. M., Broadhurst, M. K., DiBattista, J. D., Fielder, S., . . Furlan, E. M. (2021). Environmental DNA (eDNA) as a tool for assessing fish biomass: A review of approaches and future considerations for resource surveys. Environmental DNA, n/a(n/a). doi:10.1002/edn3.185

Sard, N. M., Herbst, S. J., Nathan, L., Uhrig, G., Kanefsky, J., Robinson, J. D., \& Scribner, K. T. (2019). Comparison of fish detections, community diversity, and relative abundance using environmental DNA metabarcoding and traditional gears. Environmental DNA, 1(4), 368-384. doi:10.1002/edn3.38

Sato, M., Inoue, N., Nambu, R., Furuichi, N., Imaizumi, T., \& Ushio, M. (2021). Quantitative assessment of multiple fish species around artificial reefs combining environmental DNA metabarcoding and acoustic survey. Scientific Reports, 11(1), 19477-19477. doi:10.1038/s41598-021-98926-5

Schmutz, S., Zauner, G., Eberstaller, J., \& Jungwirth, M. (2001). Die "streifenbefischungsmethode": Eine methode zur quantifizierung von fischbeständen mittelgrosser fliessgewässer. Österreichs Fischerei, 54, 14-27.

Schnell, I. B., Bohmann, K., \& Gilbert, M. T. P. (2015). Tag jumps illuminated - reducing sequenceto-sample misidentifications in metabarcoding studies. Molecular Ecology Resources, 15(6), 1289-1303. doi:10.1111/1755-0998.12402

Shu, L., Ludwig, A., \& Peng, Z. (2020). Standards for Methods Utilizing Environmental DNA for Detection of Fish Species. Genes (Basel), 11(3). doi:10.3390/genes11030296

Sigsgaard, E. E., Torquato, F., Froslev, T. G., Moore, A. B. M., Sorensen, J. M., Range, P., . . Thomsen, P. F. (2020). Using vertebrate environmental DNA from seawater in biomonitoring of marine habitats. Conservation Biology, 34(3), 697-710. doi:10.1111/cobi.13437

Soberon, J., \& Llorente, J. (1993). THE USE OF SPECIES ACCUMULATION FUNCTIONS FOR THE PREDICTION OF SPECIES RICHNESS. Conservation Biology, 7(3), 480-488. doi:10.1046/j.15231739.1993.07030480.x

Sommerwerk, N., Hein, T., Schneider-Jakoby, M., Baumgartner, C., Ostojic', A., Paunovic', M., .. . Tockner, K. (2009). The Danube River Basin. In K. Tockner, C. Zarfl, \& C. Robinson (Eds.), Rivers of Europe (pp. 59-112). Amsterdam: Elsevier Academic Press,.

Stankovic, D., Crivelli, A. J., \& Snoj, A. (2015). Rainbow Trout in Europe: Introduction, Naturalization, and Impacts. Reviews in Fisheries Science \& Aquaculture, 23(1), 39-71. doi:10.1080/23308249.2015.1024825

Takahara, T., Minamoto, T., Yamanaka, H., Doi, H., \& Kawabata, Z. (2012). Estimation of Fish Biomass Using Environmental DNA. Plos One, 7(4), 8. doi:10.1371/journal.pone.0035868

Thompson, G. G., Withers, P. C., Pianka, E. R., \& Thompson, S. A. (2003). Assessing biodiversity with species accumulation curves; inventories of small reptiles by pit-trapping in Western Australia. Austral Ecology, 28(4), 361-383. doi:10.1046/j.1442-9993.2003.01295.x

Tjorve, E. (2003). Shapes and functions of species-area curves: a review of possible models. Journal of Biogeography, 30(6), 827-835. doi:10.1046/j.1365-2699.2003.00877.x

Ushio, M., Murakami, H., Masuda, R., Sado, T., Miya, M., Sakurai, S., . . Kondoh, M. (2018). Quantitative monitoring of multispecies fish environmental DNA using high-throughput sequencing. Metabarcoding and Metagenomics, 2. doi:10.3897/mbmg.2.23297 
Valentini, A., Taberlet, P., Miaud, C., Civade, R., Herder, J., Thomsen, P. F., . . Dejean, T. (2016). Nextgeneration monitoring of aquatic biodiversity using environmental DNA metabarcoding. Molecular ecology, 25(4), 929-942. doi:10.1111/mec.13428

van Bleijswijk, J. D. L., Engelmann, J. C., Klunder, L., Witte, H. J., Witte, J. I., \& van der Veer, H. W. (2020). Analysis of a coastal North Sea fish community: Comparison of aquatic environmental DNA concentrations to fish catches. Environmental DNA, 2(4), 429-445. doi:https://doi.org/10.1002/edn3.67

Wang, S., Yan, Z., Hanfling, B., Zheng, X., Wang, P., Fan, J., \& Li, J. (2021). Methodology of fish eDNA and its applications in ecology and environment. The Science of the total environment, 755(Pt 2), 142622-142622. doi:10.1016/j.scitotenv.2020.142622

Wilcox, T. M., McKelvey, K. S., Young, M. K., Engkjer, C., Lance, R. F., Lahr, A., . . Schwartz, M. K. (2020). Parallel, targeted analysis of environmental samples via high-throughput quantitative PCR. Environmental DNA, 2(4), 544-553. doi:10.1002/edn3.80

Wilcox, T. M., McKelvey, K. S., Young, M. K., Sepulveda, A. J., Shepard, B. B., Jane, S. F., . . . Schwartz, M. K. (2016). Understanding environmental DNA detection probabilities: A case study using a streamdwelling char Salvelinus fontinalis. Biological Conservation, 194, 209-216. doi:10.1016/j.biocon.2015.12.023

Yates, M. C., Cristescu, M. E., \& Derry, A. M. (2021). Integrating physiology and environmental dynamics to operationalize environmental DNA (eDNA) as a means to monitor freshwater macro-organism abundance. Mol Ecol. doi:10.1111/mec.16202

Yates, M. C., Fraser, D. J., \& Derry, A. M. (2019). Meta-analysis supports further refinement of eDNA for monitoring aquatic species-specific abundance in nature. Environmental DNA, 1(1), 5-13. doi:10.1002/edn3.7

Yates, M. C., Glaser, D. M., Post, J. R., Cristescu, M. E., Fraser, D. J., \& Derry, A. M. (2021). The relationship between eDNA particle concentration and organism abundance in nature is strengthened by allometric scaling. Mol Ecol, 30(13), 3068-3082. doi:10.1111/mec.15543

Zajiceke, P., \& Wolter, C. (2018). The gain of additional sampling methods for the fish-based assessment of large rivers. Fisheries Research, 197, 15-24. doi:10.1016/j.fishres.2017.09.018

\section{Data Accessibility and Benefit-Sharing}

\section{Data Accessibility Statement}

The reference database sequences is available in Supporting Information Table 3. (to be completed after acceptance of the publication) and in Valentini et al. (2016). All Illumina raw sequence data and the number of reads detected for each assigned taxon in each field are available on https://doi.org/XXXXXX/dryad.pvmcv dnmr (to be deposit after acceptance of the publication). The results of electrofishing sampling at all sites are available from ICPDR (http://www.danubesurvey.org/jds4/)

\section{Benefit-Sharing Statement:}

Benefits Generated: A research collaboration was developed with scientists from the countries providing genetic samples, all collaborators are included as co-authors, the results of research have been shared with the provider communities and the broader scientific community (see above). More broadly, our group is committed to international scientific partnerships, as well as institutional capacity building. 


\section{Author contributions}

D.P., P.M., M.S., H.Z. and A.W. designed the study. M.S., H.Z., D.P. and P.M. collected the eDNA samples in the field, with the participation of M.L., C.N., L.P., B.C.S., E.S. and E.T. T.D., J.P. and A.V. conducted the laboratory and bioinformatics analyses. V.B. analysed the data related to the conventional sampling survey. D.P. assisted with data analysis, prepared the figures, and wrote most of the manuscript with significant contributions from the other authors.

\section{Additional information}

Supplementary Information accompanies this paper at http://www.nature.com/naturecommunications

Supplementary Data 1.List of 358 vertebrate studies in aquatic environments using eDNA methodologies

Supplementary Fig. 1. Quantitative longitudinal profiles of taxa detected by using eDNA (in red, Nb. eDNA copies/litre) and caught (or not) by conventional sampling (TEF, Nb. of fish caught per ha) from the source to the mouth of the Danube River $(2850 \mathrm{~km})$.

Supplementary Tab 1 . Description of the 47 sampled sites

Supplementary Tab 2 . List of reference taxa, corresponding species names, taxa name abbreviations and species caught by using TEF

Supplementary Tab 3 . Danube Reference database (to be added after publication)

\section{Competing interests}

'Teleo' primers and the use of the amplified fragment for identifying fish species from environmental samples are patented by the CNRS and the Universite Grenoble Alpes. This patent only restricts commercial applications and has no implications on the use of this method by academic researchers. SPYGEN owns a licence for this patent. T.D., P.J and A.V. are research scientists at a private company specializing in the use of eDNA for species detection.

\section{Figure captions}

Fig. 1 Location of sampling sites along the Danube (29 sites, red circles) and tributaries (18 sites, black triangles) near their confluence with the Danube.

Fig. 2 Longitudinal change in species richness along the Danube (blue line) and tributaries (red dots). Occurrences of food/aquarium fish at sites along the Danube (blue bars) and tributaries (red bars).

Fig. 3 Boxplot comparison of the taxa richness obtained from eDNA (red) and (TEF) samples at the 18 common sites. For TEF, richness is expressed at the specific-species level (dark blue) and following the taxonomic assignment used for eDNA taxa (species or species group, light blue).

Fig. 4 Between-site variability of teleo-DNA concentrations in the Danube (blue line) and the tributaries (red dots) (Fig. 4a). Relationship between teleo-DNA concentrations and mean annual waterflow at the different sites from the Danube (blue dots) and tributaries (red dots) (Fig 4b).

Fig. 5 Comparison between eDNA and traditional electrofishing methods (TEF) at the 18 common sites sampled by both methods. Regressions (type II) of teleo-eDNA concentration (mitochondrial DNA copies/L) on fish biomass (Fig. 5a) and fish density (Fig 5b) estimated by TEF. Regressions (type II) of species-specific eDNA concentration on species-specific biomass (Fig 5 c) and species-specific density (Fig 5d). 
Fig. 6 Number of eDNA copies per litre of taxa detected from the source to the mouth of the Danube River (in $\mathrm{km}$ ). Only species with a relative abundance greater than one per thousand are represented. The size of the square is a function of the concentration of the corresponding taxa-specific eDNA per litre at a given site (see Supplementary Tab 1 for taxa abbreviation list). The separation of the Upper-, Middle- and Lower-Danube sections (vertical red lines) are based on the locations of the Gabcikovo dam (KM 1029) and the Iron Gate dams I and II (KM 1908 and KM1987 respectively ${ }^{47}$.

Fig. 7 Plot of the number of taxa detected by eDNA against the number of teleo-DNA copies per sample for the 47 sites. Fitted curves from parameters estimated from a non-linear mixed model at the population level (black line) and individual level (red lines: tributaries, blue lines: Danube River). Longitudinal distribution of species.

\section{Figure 1}

Fig. 1 Location of sampling sites along the Danube (29 sites, red circles) and tributaries (18 sites, black triangles) near their confluence with the Danube.

\section{Figure 2}

Fig. 2 Longitudinal change in species richness along the Danube (blue line) and tributaries (red dots). Occurrences of food/aquarium fish at sites along the Danube (blue bars) and tributaries (red bars).

\section{Figure 3}

Fig. 3 Boxplot comparison of the taxa richness obtained from eDNA (red) and (TEF) samples at the 18 common sites. For TEF, richness is expressed at the specific-species level (dark blue) and following the taxonomic assignment used for eDNA taxa (species or species group, light blue).

\section{Figure 4}

Fig. 4 Between-site variability of teleo-DNA concentrations in the Danube (blue line) and the tributaries (red dots) (Fig. 4a). Relationship between teleo-DNA concentrations and mean annual waterflow at the different sites from the Danube (blue dots) and tributaries (red dots) (Fig 4b). 


\section{Figure 5}
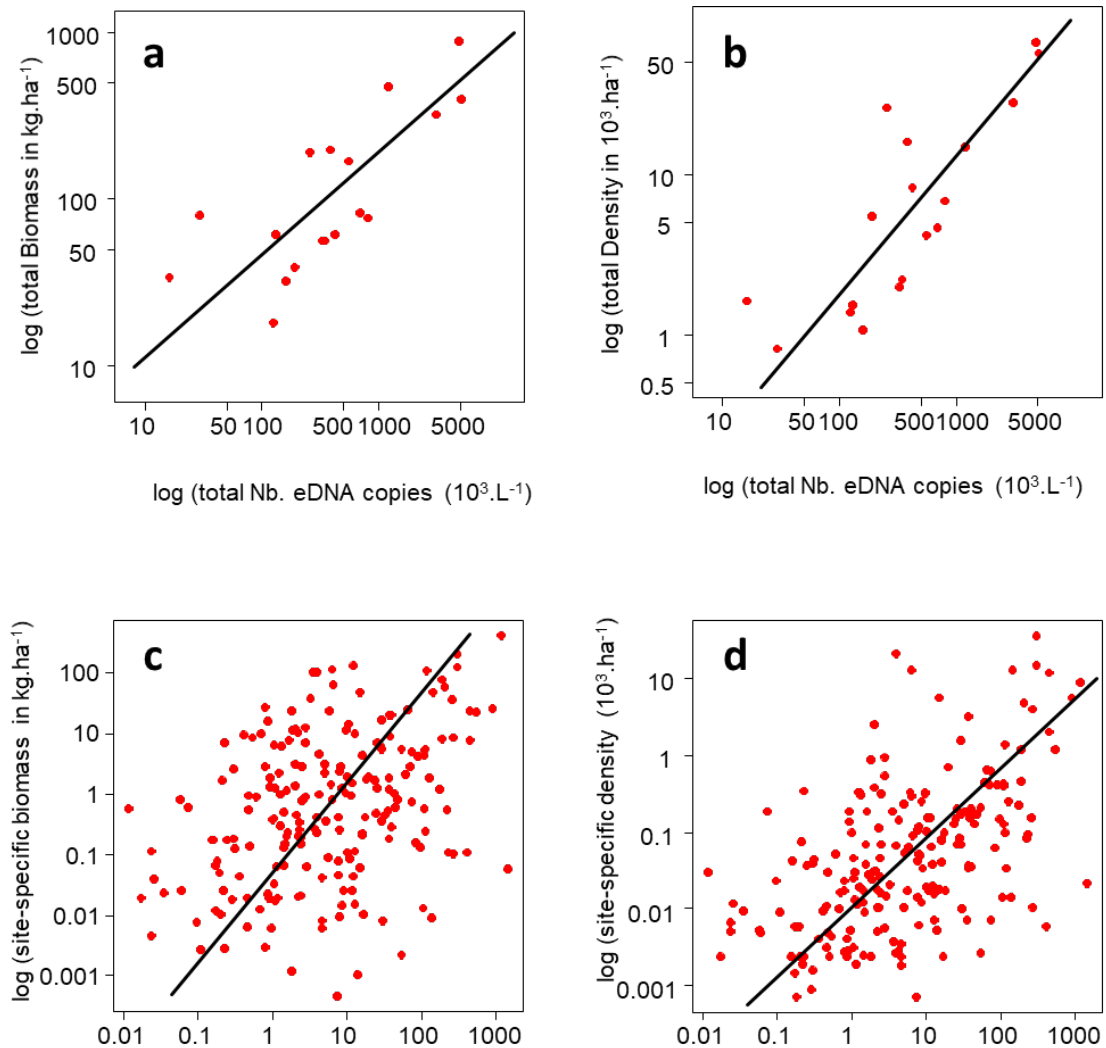

$\log \left(\mathrm{nb}\right.$. specific eDNA copies per site $\left.\times 10^{3} \cdot \mathrm{L}^{-1}\right)$

$\log \left(\mathrm{nb}\right.$. specific eDNA copies per site $\left.\times 10^{3} \cdot \mathrm{L}^{-1}\right)$

Fig. 5 Comparison between eDNA and traditional electrofishing methods (TEF) at the 18 common sites sampled by both methods. Regressions (type II) of teleo-eDNA concentration (mitochondrial DNA copies/L) on fish biomass (Fig. 5a) and fish density (Fig 5b) estimated by TEF. Regressions (type II) of species-specific eDNA concentration on species-specific biomass (Fig 5 c) and species-specific density (Fig 5d). 


\section{Figure 6}

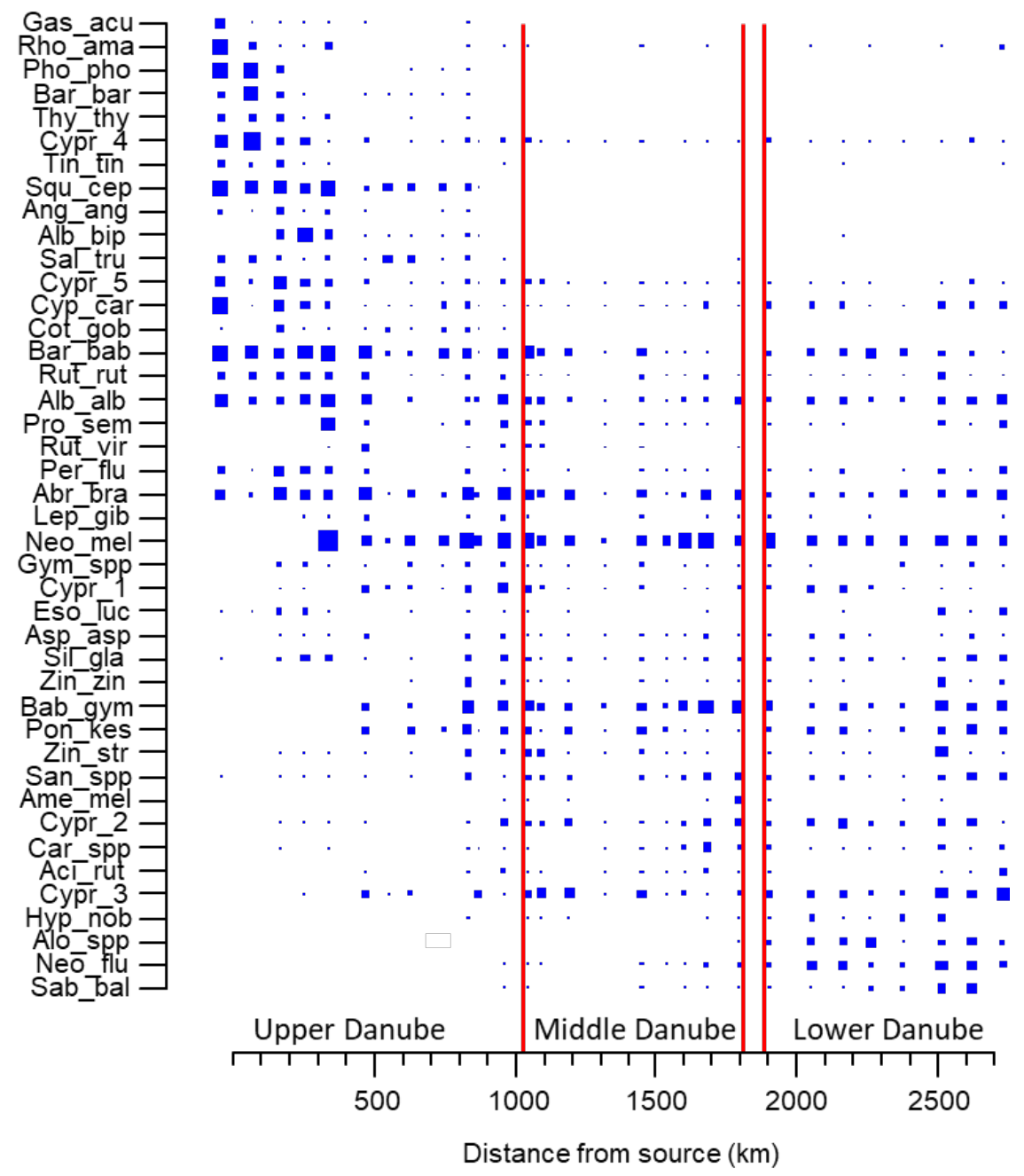

Fig. 6 Number of eDNA copies per litre of taxa detected from the source to the mouth of the Danube River (in km). Only species with a relative abundance greater than one per thousand are represented. The size of the square is a function of the concentration of the corresponding taxa-specific eDNA per litre at a given site (see Supplementary Tab 1 for taxa abbreviation list). The separation of the Upper-, Middle- and Lower-Danube sections (vertical red lines) are based on the locations of the Gabcikovo dam (KM 1029) and the Iron Gate dams I and II (KM 1908 and KM1987 respectively) ${ }^{47}$. 
Figure 7

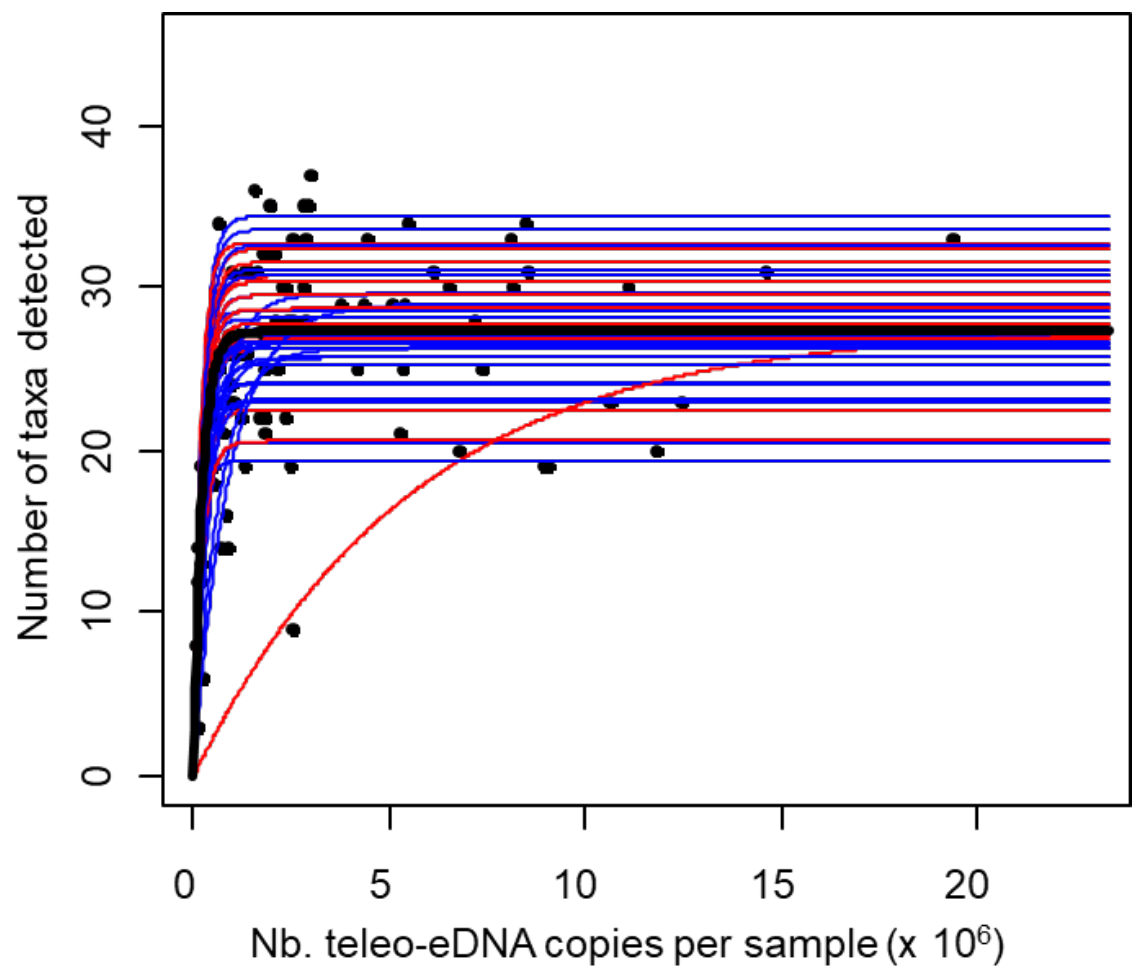

Fig. 7 Plot of the number of taxa detected by eDNA against the number of teleo-DNA copies per sample for the 47 sites. Fitted curves from parameters estimated from a non-linear mixed model at the population level (black line) and individual level (red lines: tributaries, blue lines: Danube River). Longitudinal distribution of species. 